\title{
Simposium tussen Nederlandse en Suid-Afrikaanse Nuwe-Testamentici: verslag en kritiese evaluering
}

A B du Toit

\section{ABSTRACT}

Symposium between Dutch and South African New Testament scholars: report and critical evaluation

A short historical sunvey of theological relations between Netherland and South Africa and especially of the consequences of the cultural boycott, highlights the importance of this meeting. The papers read at the meeting and some of the prominent issues, as well as deliberations on the possibility of future academic cooperation, are presented and evaluated.

\section{AGTERGRONDSKETS}

Om die simposium van Nederlandse en Suid-Afrikaanse Nuwe-Testamentici op 2-3 Augustus 1993 te Utrecht binne die regte historiese perspektief te plaas is 'n kort agtergrondskets noodsaaklik.

Die onderlinge band tussen Nederlandse en Suid-Afrikaanse teoloë gaan ver terug. In die lig van die ontstaansgeskiedenis van die Suid-Afrikaanse kerke van Gereformeerde tradisie is dit eintlik 'n vanselfsprekendheid. Nog tot diep in die negentiende eeu was die meerderheid predikante wat gemeentes alhier bedien het, alumni van Nederlandse teologiese inrigtings. Na die stigting van die Teologiese Seminarium te Stellenbosch in 1859 sou heelwat afgestudeerde leraars nog steeds na Nederland gaan vir gevorderde studie.

Rondom die eeuwende was dit by uitstek Utrecht en Leiden wat jong Suid-Afrikaanse teoloë getrek het. Hierna kom daar egter 'n kentering. Uit reaksie teen die liberalisme, wat ook aan die Kaap sy invloed laat geld het, en onder invloed van die hernieude klem op die belydenisskrifte wat met die afskeidingsbeweging in Nederland gepaard gegaan het, wend nou steeds meer studente hulle na die Vrije Universiteit en later na Kampen. Slegs enkeles, waaronder veral jong teoloë uit die Ned Herv Kerk, sou nog in Utrecht en Leiden afstudeer.

Wat Nuwe-Testamentici in besonder betref, het verskeie in die eerste helfte van ons eeu hulle studie onder Professor Grosheide in Amsterdam voltooi. Daarna lei die meeste weë na Kampen, waar Professor Ridderbos die groot aantrekkingskrag geword het. Oor die drie dekades vanaf 1959 promoveer agt Suid- 
Afrikaanse Nuwe-Testamentici te Kampen. Die laaste twee van hierdie agt is verteenwoordigers uit die bruin (G D Cloete) en die swart gemeenskap (L W Mazamisa). Die toevloei van doktorale studente in die Nuwe Testament uit die blanke Afrikaanssprekende gemeenskap het reeds in 1972, na Willem Nicol se promosie, opgehou. Sedertdien het nog geen ander Nuwe-Testamentikus uit laasgenoemde gemeenskap in Nederland afgestudeer nie. Een van die belangrikste redes hiervoor was die verbreking van kulturele bande as gevolg van die apartheidstelsel.

Wat op studentevlak gegeld het, was ook waar ten opsigte van dosenteverhoudings. Op informele vlak kon daar wel sporadiese kontak plaasvind. Op formele vlak was wisselwerking slegs moontlik met kollegas uit die bruin en swart gemeenskappe.

In die lig van ons gemeenskaplike kulturele, geloofs- en teologiese erfenis is dit duidelik dat hierdie 'n diep ongelukkige stand van sake was, en dat albei kante in die proses skade gely het. Juis daarom was dit so besonder verblydend, en inderdaad 'n historiese mylpaal, toe bogenoemde simposium 'n werklikheid word.

\section{2 'N BREë KARAKTERISERING VAN DIE SIMPOSIUM}

Die simposium het plaasgevind op die aantreklike nuwe kampus van die Rijksuniversiteit van Utrecht met professor Pieter van der Horst as die bekwame gasheer. Die bekendste Nederlandse teologiese fakulteite was almal verteenwoordig: Utrecht deur professor van der Horst, Leiden deur professor $\mathbf{H} \mathbf{J}$ de Jonge en professor-emeritus $M$ de Jonge, die Vrije Universiteit deur professor $T$ Baarda, die Theologische Universiteit van Kampen deur professor $C \mathrm{~J}$ den Heyer, die Universiteit van Groningen deur professor A S van der Woude ('n Ou-Testamentikus), die Universiteit van Nijmegen deur professor $\mathrm{S}$ van Tilborg en die Universiteit van Amsterdam deur professor $\mathrm{J}$ W van Hentem. As gevolg van diverse faktore buite beheer van die organiseerders van die simposium (professore Van der Horst en Du Toit), was die Suid-Afrikaanse verteenwoordigers ongelukkig minder eweredig versprei: professore G M M Pelser, J G van der Watt, S J Joubert en A B du Toit van die Universiteit van Pretoria, professor H J B Combrink en dr J Botha van die Universiteit van Stellenbosch, professor W A Sebothoma en dr P F Craffert van die Universiteit van Suid-Afrika, professor J A du Rand van die Randse Afrikaanse Universiteit, dr L W Mazamisa van die Universiteit van Kaapstad en dr D F Tolmie van die Universiteit van die O V S.

Die doelstellings van die byeenkoms was eerstens om beter met mekaar se werk kennis te maak en tweedens om moontlikhede van samewerking te verken. Met die oog hierop is drie referate aan albei kante aangebied wat nader ingegaan het op die werk wat in die onderskeie lande gedoen word. Daarbenewens het $\mathrm{dr}$ 
Craffert ook nog 'n kortreferaat voorgelê. Aan die einde van die simposium is ook 'n bespreking gevoer oor moontlikhede vir toekomstige samewerking.

INHOUDELIKE OORSIG EN EVALUERING

Om 'n meer samehangende beeld te gee van die werk wat in albei lande gedoen word, word agtereenvolgens eers die drie Nederlandse referate aan die orde gestel en daarna die vier Suid-Afrikaanse aanbiedings.

Professor Marinus de Jonge, die senior Nederlandse Nuwe-Testamentikus teenwoordig, moes in sy referaat 'n breë oorsig gee oor die stand van die NuweTestamentiese wetenskap in Nederland. Hy het eerstens gewys op die belang as inligtingsbron van die groot aantal Festschriften, biografiese en in memoriam-artikels wat tussen 1953 en 1992 verskyn het in verband met die persoon en werk van De Zwaan, G Sevenster, Van Stempvoort, J N Sevenster, Schippers, Ridderbos, Grossouw, Van Unnik, Doeve, Kahmann, Bouwman, Klijn, Van Iersel, De Jonge en Baarlink. Hierdie publikasies bevat 'n goudmyn van inligting oor die persone wat die Nuwe-Testamentiese arbeid in Nederland vir baie jare oorheers het. Sommige van hierdie publikasies bevat ook andersins moeilik bekombare artikels van bogenoemde geleerdes.

De Jonge beskou die tydperk rondom 1960 as die eerste fase van die tydperk onder diskussie. Dit was juis die tydperk waarin bogenoemde geleerdes die botoon gevoer het, alhoewel sommige van hulle reeds vroeër die hoogtepunt van hulle arbeid bereik het. De Jonge beskou die volgende kenmerke as tiperend van hierdie eerste tydperk: deeglike filologiese studie, 'n warsheid aan hiperkritiek, weinig sin vir metodologiese kwessies, 'n sterker gerigtheid op die Anglosaksiese as op die Duitse Nuwe-Testamentiese arbeid, 'n sterk kerklike betrokkenheid. Wat die objek van hulle studieveld betref, het dit, globaal gesproke, primêr gegaan om die kanonieke boeke van die Nuwe Testament.

Die daaropvolgende tydperk, wat nog tot op die hede voortgaan, is ingrypend beïnvloed deur die demokratiseringsproses in die universiteitswese en die groterwordende klem op maatskaplike relevansie. Dit het onder meer meegebring dat 'n gedeë kennis van Grieks en Hebreeus nie meer soos voorheen 'n vanselfsprekende onderbou vir teologiestudie sou uitmaak nie. Maatskaplike omwentelinge het boonop 'n groter wantroue in die establishment gebring en daarmee saam ook in die kerk. Dit het op sy beurt 'n groter afstand tussen die teologiese ondersoek en die kerk meegebring.

'n Toeristiese verkenning van die Nuwe-Testamentiese arbeid aan die onderskeie teologiese inrigtings dui op 'n buitengewone sterk konsentrasie op die buite-kanonieke literatuur en gevolglik op die Umwelt van die Nuwe Testament. Die fokus val onder meer op die Testament van die Twaalf Patriarge, Koemraun, 
asmede (ander) relevante Joods-Hellenistiese en Griekse tekste (vgl die groot Corpus Hellenisticum-projek). Ook die tekskritiek kry besondere aandag (Baarda, $\mathrm{H}$ $\mathrm{J}$ de Jonge).

Die tendens om op die buite-kanonieke literatuur rondom die NuweTestamentiese tydvak te konsentreer word verder bevestig deur die referaat van Van der Woude onder die tema "Ontwikkelingen in de judaïstiek in Nederland in de afgelopen decennia". Laasgenoemde, wie se eie doktorale proefskrif gegaan het oor Die messianischen Vorstellungen der Gemeinde von Qumran, laat die klem val op die belangrike werk wat in Groningen op die Dooie-Seerolle gedoen word. Hy beklemtoon ook die besondere akademiese belang van die werk van die bekende Utrechtse geleerde W C van Unnik aan die Corpus Hellenisticum, soos voortgesit deur G Mussies en veral Van der Horst. Laasgenoemde se onlangse arbeid op die epigrafie verdien besondere vermelding. Verder word van Nederlandse kant 'n belangrike bydrae gelewer tot die Compendia Rerum Iudaicarum ad Novum Testamentum, waaraan onder meer verskeie Joodse geleerdes meewerk.

As dit korrek is dat agtergrond- en tekskritiese studie elders sterker aan die bod kom as linguistiese en literêre gesigspunte, dan geld dit nie van die werk te Nijmegen nie. In sy referaat getitel "Literaire benaderingen van het Nieuwe Testament in Nederland", wys Sjef van Tilborg daarop dat persone soos Van Unnik en Ridderbos wel in 'n mate aandag gegee het aan literêre gesigspunte. Die invloed van die energieke en telkens-sigself-korrigerende Mieke Bal kan egter veral in die werk van Ou-Testamentici soos Beuken en Fokkelman nagespoor word. Die bydrae van die Nederlandse Nuwe-Testamentici ten opsigte van die linguisties-literêre ondersoek van die Nuwe Testament is egter minder "flambojant". In sy "hand-out" oor Nederlandse werk op hierdie gebied tree twee geskrifte van die Kampense Nuwe-Testamentikus Cees den Heyer na vore. Dit is egter veral in Nijmegen waar op hierdie veld gewerk word. Voorheen was Van Iersel sterk hierby betrokke, en nou ook spreker self. 'n Lys van ter sake ondersoekprojekte word ter kennisname voorgelè.

Terugskouend op die beeld van die Nederlandse Nuwe-Testamentiese ondersoek soos tydens die simposium geteken, bly die sterk klem op tekskritiek en die buite-kanonieke literatuur steeds opvallend. Later, wanneer die Suid-Afrikaanse beofening van die Nuwe-Testamentiese ondersoek aan die orde gestel word, sal die kwessie van 'n sekere eensydigheid weer eens aan bod kom. Laasgenoemde is tydens die kongres aangeroer, maar kon nie breedvoerig bespreek word nie. Aan die eensydigheid op die Nederlandse toneel kon ongelukkig geen aandag gegee word nie. Daarmee word natuurlik vir geen oomblik beweer dat die betrokke inrigtings geen aandag aan die Nuwe Testament self gee nie. Spesialisasie bly egter die voedingsbron vir ' $n$ verrykte verstaan van die Nuwe Testament self. In hierdie opsig kan dit nie ontken word nie dat dit hoofsaaklik Ridderbos en 'n paar meer 
konserwatiewe kollegas was wat die hoofklem op 'n inhoudelik-teologiese ondersoek van die Nuwe Testament laat val het.

Oor die redes vir hierdie tendens kan slegs vermoedens uitgespreek word. Sou dit wees omdat die studie van die tekskritiek en die buite-kanonieke dokumente 'n groter moontlikheid vir ontdekkende navorsing bied? Sou dit wees dat 'n groeiende bewuswording van historiese probleme ten opsigte van die Nuwe-Testamentiese dokumente self hierdie 'n baie sensitiewe terrein maak? Die indruk kan moeilik vermy word dat daar in Nederland op die gebied van die intensiewe bestudering van die Nuwe Testament self, wat immers qua definisie die konsentrasiepunt van ons vakgebied uitmaak, 'n behoefte aan groter spesialisasie bestaan. Hierdie kwessie hang vermoedelik ook saam met die vraag na die kerklike verantwoordelikheid van die teologie. As dit so sou wees - en dit is skrywer se oortuiging dat die teologie en daarom ook die Nuwe-Testamentiese wetenskap 'n sterk kerklike verantwoordelikheid het, moet die intensiewe bestudering van die Nuwe Testament self steeds die fokuspunt bly, en sal die studie van die Umwelt 'n belangrike hulpdissipline, maar dan ook inderdaad ' $n$ hulpdissipline wees. Ek is ook van mening dat meerdere aandag vir die linguisties-literêre en verwante metodologiese gesigpunte slegs verrykend sou kon inwerk.

Aan die positiewe kant moet terselfdertyd gestel word dat die bekwaamheid en erns waarmee die relevante buite-kanonieke bronne in Nederland hestudeer word en die uiters waardevolle insigte aangaande die Joodse en Joods-Hellenistiese voedingsbodem van die Nuwe Testament wat hierdeur ingewin word, nie alleen reeds 'n aansienlike bydrae tot die Nuwe-Testamentiese wetenskap opgelewer het nie, maar Nederland ook 'n uiters geskikte land vir gespesialiseerde studie op hierdie terrein maak.

Die Suid-Afrikaanse bydrae is begin met 'n algemene oorsig oor die opkoms en huidige stand van die plaaslike Nuwe-Testamentiese ondersoek. Die grootste probleem met die referaat van Du Toit oor hierdie tema was die tyd- en spasiebeperking wat 'n geleentheid soos hierdie noodwendig meegebring het. Gevolglik moes uiters selektief te werk gegaan word, en het slegs die mees opvallende aspekte aandag geniet. Die feit dat hy aan die belangrikste metodologiese tendense aandag moes gee, het meegebring dat die teologies-inhoudelike arbeid aan die onderskeie Nuwe-Testamentiese boeke en die breër Nuwe-Testamentiese corpora onderbelig is en die aangehegte bibliografie 'n heeltemal onvolledige prentjie gee. Wat die Matteus- en die Johannesnavorsing betref, kon hierdie leemte gelukkig deur die latere referate aangevul word.

Du Toit beskou die jaar 1965, waarin die Nuwe-Testamentiese Werkgemeenskap van Suid-Afrika gestig is, as 'n belangrike keerpunt waaromheen die ontwikkeling van die plaaslike Nuwe-Testamentiese ondersoek in twee fases verdeel kan word. In die pioniertydperk figureer persone soos Johannes du Plessis, 
Greyvensteyn en later Groenewald, Snyman en Geyser sterk. Die inhiberende uitwerking van die Du Plessisstryd word geskets, asook die leidende rol van Groenewald.

Die tweede tydperk word gekenmerk deur die toetrede van 'n nuwe geslag Nuwe-Testamentici en die dinamiese groei en positiewe rol van die Nuwe-Testamentiese Werkgemeenskap. 'n Ware ontploffing van proefskrifte en Nuwe-Testamentiese navorsingsartikels vind plaas, sterk gekenmerk deur 'n opvallende soektog na bevredigende metodes. Aanvanklik kry die linguistiek, en in besonder die diskoersanalise, onder invloed van J P Louw sterk aandag, maar mettertyd kring die soektog uit na alle relevante metodes, insluitende, in die jongste tyd, die historiese paradigma. Hierdie Nuwe-Testamentiese publikasies kan tereg gekritiseer word op grond van 'n te sterk en dikwels eensydige klem op die metodologiese, asook 'n gebrekkige teologiese en maatskaplike relevansie. Nietemin het daar tog, soos reeds geïmpliseer is, 'n nie-onaansienlike hoeveelheid inhoudelik-teologiese publikasies verskyn en begin sterker eietyds-betrokke produksies nou hulle verskyning maak.

Bernard Combrink, wat bestempel kan word as die voorste plaaslike eksponent van Matteusnavorsing, se tema was "Resente Matteusnavorsing in SuidAfrika". Die metodologiese soektog, wat so tipies van die Suid-Afrikaanse NuweTestamentiese arbeid is, het ook op die Matteusnavorsing sy stempel afgedruk: die redaksie-historiese, die diskoersanalitiese, die literêr-kritiese, die narratologiese, sowel as die onderskeie pragmatiese benaderings het almal aandag gekry. Waar die Nuwe-Testamentiese arbeid kritiek moes verduur omdat dit te min eietyds betrokke is, vertoon die geskiedenis van die Matteusnavorsing tog 'n enigsins verskillende beeld, soos blyk uit die sterk kontekstuele bydraes van Cloete, Suggit, Jacob, Domeris, Nicol, Smit en Boesak. Rakende die Afrika-konteks en meer spesifiek die Afrika-leser se resepsie van Matteus, moet egter nog veel gedoen word. Combrink tipeer ook die vordering wat daar gemaak is met die daarstelling van Matteus se teologie en etiek, en wys in hierdie verband krities op sy eie groei.

Die referaat van Jan van der Watt, met as tema "Johannese navorsing in Suid-Afrika. 'n Enkele teologiese perspektief", vul die leemte in Du Toit se aanbieding ten opsigte van die Johannese navorsing nie net aan nie, maar gaan voort om, in aansluiting by sy artikel in die Du Toit-feesbundel: "Die Woord het Mens geword: 'n strukturele uiteensetting van die teologie van die Johannesevangelie" (in J H Roberts, W S Vorster, J N Vorster, J G van der Watt (reds) 1991, Teologie in konteks, 1991 Pretoria, 93-130), op kreatiewe wyse te illustreer hoe literêre en sosio-kulturele insigte die teologiese verstaan van die Johannesevangelie kan bevorder. Hy karakteriseer die wyse waarop Johannes sy teologie aanbied, as "piktoraal-sistemies". Met "piktoraal" word in hierdie verband gedui op die Johannese metafoorgebruik, terwyl die term "sistemies" aandui dat Johannes sy 
teologie nie deur middel van losstaande metafore vergestalt nie, maar juis deur middel van onderling-verbonde metafoorkomplekse, soos die van skaapboerdery (Johannes 10) of 'n wingerdbedryf (Johannes 15). Waar die sendingmetafoorkompleks reeds in sy vorige artikel prominent was, word nou die familiemetafoornetwerk uitgebou as een van die deurslaggewende sleutels vir die verstaan van die Johannese teologie en etiek. Terselfdertyd stel hierdie insigte duidelik die organiese eenheid en kohesiewe karakter van die Johannese denke bo alle twyfel.

Met sy onderwerp "'n Herdefiniëring van Paulus se konflik in Galasië", wat die bevindinge in sy 1992 doktorale proefskrif ("A social-scientific key to Paul's letter to the Galatians: An alternative to opponent hypotheses as a cypher key". DTh thesis. University of South Africa) heropneem, wil Pieter Craffert wegbeweeg van die tradisionele beheptheid met opponente en hulle botsende standpunte na 'n benadering wat die aard van die konflik vanuit sosiaal-wetenskaplike perspektief herdefinieer. Vanuit hierdie hoek probeer hy aantoon dat Paulus se Anliegen nie so seer was om 'n teologiese argument te wen nie, maar om sy eie gesag en posisie binne die sosiale realiteite waarin hy en die Galasiërs hulle bevind het, deur middel van 'n beroep op tradisies, gesagsimbole en openbarings te bevestig.

In reaksie op Du Toit se referaat is van Nederlandse kant gevra na die rede vir die Suid-Afrikaners se sterk konsentrasie op die linguisties-literêre en verwante paradigmas. Sou die rede geleë wees in 'n sterk konserwatiewe Skrifbeskouing wat die diachroniese vraagstellings vrees? Myns insiens mag daar in hierdie vraag 'n element van waarheid wees. Tog is ek van mening dat die beslissende rede elders lê, naamlik by die behoefte om, na die relatief-ongereflekteerde eksegese van vroeër, op 'n meer verantwoorde wyse by die semantiese valensies van die Skrifteks te probeer uitkom. Hieruit blyk ook alreeds die kerklike gerigtheid - oor die algemeen gesproke - van die plaaslike eksegese. Terselfdertyd het hierdie kerklike gerigtheid in die verlede duidelik inhiberend ingewerk op historiese vraagstellings. Die ideale posisie sou myns insiens wees, soos ook in my referaat gestel, 'n gesonde dialektiek tussen geloof en rede.

Juis laasgenoemde stelling, naamlik van die geloof as 'n teoretiese vertrekpunt en as een element in 'n dialektiese verhouding waarbinne geloof en rede die twee pole uitmaak, het egter ook, sy dit op heel beperkte wyse, in die diskussie onder skoot gekom. Waar' $n$ geloofsrelasie tot ons studie-objek voorheen as 'n vanselfsprekende vertrekpunt gegeld het, is dit vandag nie meer noodwendig die geval nie. Hierdie tendens tree nie net in Suid-Afrika na vore nie, maar is nog sterker internasionaal waar te neem. Hierdie realiteit moet ernstig geneem word. Daar sal eerlik en indringend met hierdie Bybelwetenskaplikes in gesprek getree word oor die aard van teorievorming in die wetenskap. 'n Sogenaamde neutraalwetenskaplike benadering tot die Bybel is 'n hersenskim. Wie meen dat hy dit beoefen, vertrek ten diepste van 'n anti-metafisiese voorveronderstelling. Hierdie 
probleem sny baie diep. Dit bring ons by die godsdiensfilosofiese grondslae van alle teologie-beoefening en uiteindelik die skeidingspunt tussen teologie en godsdienswetenskap.

In die sowat anderhalf uur wat aan die einde opsygesit is vir die bespreking van onderlinge samewerking, is verskeie vlakke en moontlikhede van samewerking bespreek: studente-uitruilprogramme, dosente-uitnodigings, oor-enweer finansiële tegemoetkoming, ensomeer. Die moontlikheid van gesamentlike arbeid aan byvoorbeeld kommentaarreekse het nie, soos deur sommige in vooruitsig gestel, aan die orde gekom nie. Ook andersins kon nie tot meer konkrete vorms van samewerking gekom word nie. Waarskynlik was die tyd daarvoor nog nie ryp nie. Onderlinge kennis en vertroue sal eers nog verder opgebou moet word. Daar is egter wel besluit om weë te probeer vind om 'n vaste jaarlikse ontmoeting moontlik te maak, maar dan binne die raamwerk van reeds bestaande strukture.

As finale, oorkoepelende evaluering: Die simposium tussen Nederlandse en Suid-Afrikaanse Nuwe-Testamentici kan beskryf word as 'n uiters geslaagde, aktuele en sinvolle gebeurtenis wat veel belofte inhou vir die toekoms van die Nuwe-Testamentiese wetenskap in albei lande. Die eerste onseker treë is immers reeds gegee. Hierop kan tot almal se voordeel voortgebou word.

Dit sou waarskynlik goed wees as hierdie ontmoeting deur soortgelyke byeenkomste op ander vakgebiede opgevolg kon word. 